Proc. Estonian Acad. Sci. Geol., 2004, 53, 2, 67-93

\title{
Effect of the GRACE satellite mission on gravity field studies in Fennoscandia and the Baltic Sea region
}

\begin{abstract}
Artu Ellmann
Geodesy Group, Department of Infrastructure, Royal Institute of Technology, SE-100 44 Stockholm, Sweden; ellmann@geomatics.kth.se

Present address: Geodetic Research Laboratory, Department of Geodesy and Geomatics Engineering, University of New Brunswick, PO Box 4400, Fredericton, NB, Canada E3B 5A3; ellmann@ unb.ca

Received 3 October 2003, in revised form 19 January 2004

Abstract. It is customary to utilize the Earth's artificial satellites for detecting long-wavelength components of the Earth's gravity field. The tracking data of the GRACE twin-satellites are the basis of the new geopotential model GGM01, released by the Centre for Space Research at the University of Texas in July 2003. The present paper assesses the quality of the GGM01 model through comparisons with an earlier geopotential model (EGM96). The method of spherical harmonic expansions is used in numerical investigations. The results of evaluation in Fennoscandia and the Baltic Sea region illuminate the discrepancies between the long-wavelength contributions of the models, which may reach several decimetres in the geoidal heights. Thus, even in the gravimetrically well studied area like the Baltic Sea region, the new satellite gravity missions may improve the gravity data significantly. Tests with high-precision GPS-levelling data indicate the offsets between global geoid models and national vertical datums in the Baltic Sea region. The gravity anomaly grid and the GGM01 model are utilized in the computation of the Estonian gravimetric geoid model by the least squares modification of Stokes' formula. The new model EST-03 is fitted to a set of 26 high-precision GPS-levelling points, yielding a root mean square error of $3 \mathrm{~cm}$ for the post-fitting residuals. This order of discrepancies is sufficient for many practical and scientific applications.
\end{abstract}

Key words: geopotential model, GRACE, gravimetric geoid, Stokes' formula, least squares modification, GPS-levelling, Estonia.

\section{INTRODUCTION}

The central task of geosciences is studying the Earth as a complex system composed of solid, fluid, and gaseous parts, between which composite interactions take place. A physical model of the Earth should combine many elements, among which an accurate description of the gravitational field and its spatial and 
time-dependent variations are essential. The gravity data, such as gravity anomalies, or geoidal heights, are only one source of information used in geophysical interpretations. Seismological, magnetic, electrical, and heat flow data are alternative sources. Although the gravity data can be collected with almost any required sampling density, the gravity field parameters for the entire Earth were not well known until recent past. Particularly troublesome in this respect were vast ocean areas, covering $70 \%$ of the surface of the planet.

The gravity field characteristics can be defined from the accurate tracking of artificial satellites. In particular, the satellites are very useful for detecting the long-wavelength component of the Earth's gravitational potential. This potential is conveniently expressed as a series expansion of spherical harmonics, and such a model is called a global geopotential model (GGM). Recently, new geopotential models have become available, which were computed including data from new satellite gravity missions, such as CHAMP (CHAllenging Minisatellite Payload) and GRACE (Gravity Recovery and Climate Experiment).

In this paper the impact of the GRACE data on some GGM applications is studied and discussed. We begin with some relevant background information, followed by a short description of two geopotential models under study. Due to availability, quality, and type of data, the characteristics of a GGM vary regionally. Hence, the performance of any model needs to be validated in regional (or local) scale. The focus of this study is on Fennoscandia and the Baltic Sea region.

The applicability of different gravity field parameters to studies of the Earth's interior is discussed in Section 3. A useful application of the GGM is to determine the gravimetric geoid model. The geoid is defined as an equipotential surface of the Earth's actual gravity field, (generally) inside the topographical masses on land and more or less coinciding with mean sea level at sea. The geoid plays an essential role in the geodetic infrastructure, as the topographic heights and the depths of the seas are reckoned from it. The improved knowledge of the geoid model can contribute to many applications of Earth studies, including also the long-term geophysical processes (post-glacial rebound, plate tectonics, mantle convection, etc.). Section 4 concerns the numerical investigations. The results of several tests are presented and discussed. First, the contributions of some selected spectral windows of two different geopotential models are assessed and their discrepancies compared. Second, two sets of high-precision GPS-levelling data are applied to an independent evaluation of the geoid models, derived from the GGM.

In the determination of regional geoid models it has become customary to employ modified Stokes' formula, which combines local gravity data with a GGM. Here the new GRACE Gravity Model GGM01 is utilized for computing a highresolution geoid model for Estonia. Thereafter the results are compared with the GPS-levelling control points and an earlier geoid model for the same area. The computations of the latter employ essentially the same computational setup and local gravity data, but differently, the Earth Gravitational Model EGM96 (Lemoine et al. 1998). It will be demonstrated that the numerical tests support the suitability of GGM01 for high-resolution geoid modelling. Finally, a short conclusion follows. 


\section{THE STUDY AREA}

The performance of the geopotential models is examined in the region, which includes Fennoscandia, the Baltic Sea and its coastal areas (Fig. 1). The countries involved, entirely or partly, are Belarus, Denmark, Estonia, Finland, Germany, Latvia, Lithuania, Norway, Poland, Russia, and Sweden. Geographical boundaries of this region are from $53^{\circ}$ to $72^{\circ}$ northern latitudes, and from $5^{\circ}$ to $40^{\circ}$ eastern longitudes. The study area is geologically, geophysically, and geodetically one of the best-studied regions on the globe. A great number of publications exist addressing local and regional geodynamical processes. Thus, only a few sample references, relevant to our study, are cited in this paper when appropriate.

In the study area, the geoidal heights range from 9 to $47 \mathrm{~m}$, whereas the general pattern of the geoid is an eastward "down-slope" of the order of 1 to $4 \mathrm{~cm} / \mathrm{km}$ (Fig. 1). As is well known, Fennoscandia is affected by a post-glacial land uplift with a maximum rate of about $1 \mathrm{~cm} / \mathrm{yr}$. This leads to an obvious paradox. While the land uplift suggests a mass deficit, the regional geoidal heights are positive, suggesting a mass excess. It should be noted that post-glacial rebound

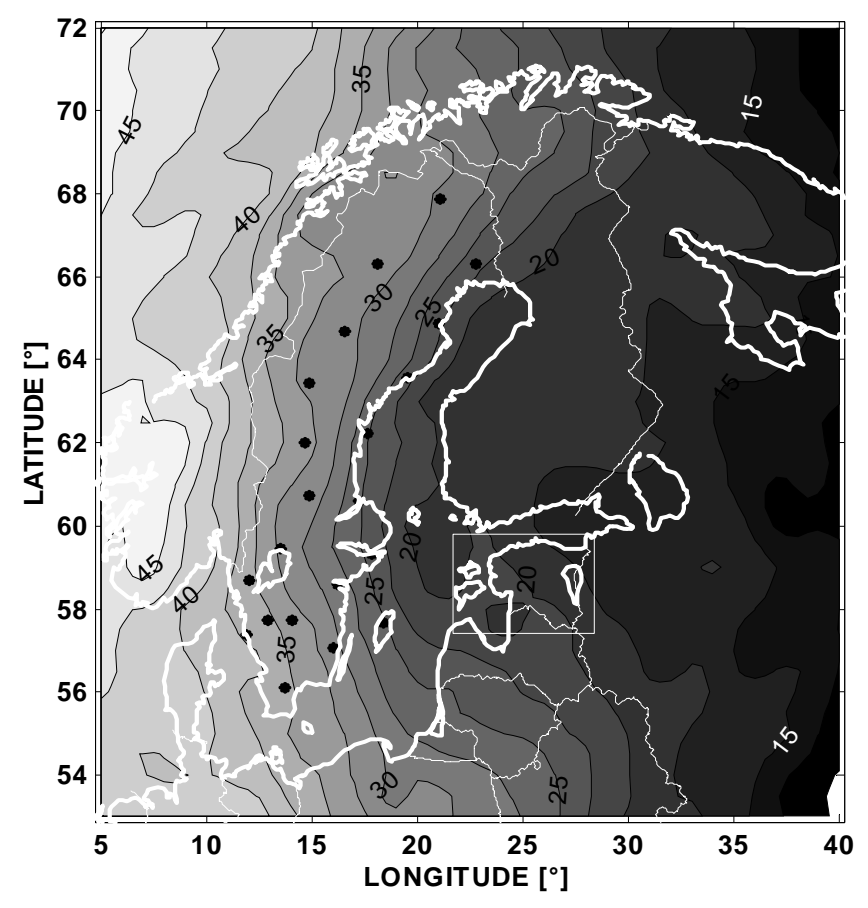

Fig. 1. Geoid model of the study area. Geoidal heights are given with respect to the GRS-80 reference ellipsoid. Unit is metre and the contour interval is $2.5 \mathrm{~m}$. The small test area, Estonia, is enclosed by the rectangle. Black dots indicate the location of Swedish GPS-levelling points. 
results not only in land uplift, but also in gravity and geoidal changes (see, e.g., studies by Sjöberg 1982; Ekman \& Mäkinen 1996, among many others). It should also be noted that the depth of the Mohorovičić discontinuity surface (or simply Moho) in the study area is greater (regional minimum reaches $60 \mathrm{~km}$ ) than usual in the continental regions without high mountain ranges. The Moho depth and the apparent land uplift maps are not reproduced in this paper. The interested reader is referred to original sources: see, e.g., Kakkuri (1997) for the Fennoscandian land uplift map, Luosto (1997) for recent Moho depth models.

Inside the study region a small test area was selected - Estonia (Fig. 1). The high-resolution geoid model for Estonia was computed, and thereafter applied to evaluation of the geopotential models. The total area of Estonia is approximately $45200 \mathrm{~km}^{2}$ (including inner waters and islands), the elevation extremes are $0 \mathrm{~m}$ at shoreline and $318 \mathrm{~m}$ in southeast Estonia. Geographical limits of the test area are from $57.5^{\circ}$ to $59.7^{\circ}$ northern latitude and from $21.8^{\circ}$ to $28.3^{\circ}$ eastern longitude. In addition to the Estonian mainland and islands, it $\left(\sim 83500 \mathrm{~km}^{2}\right)$ involves part of the Baltic Sea, northern Latvia, and a small part of northwestern Russia. About $94 \%$ of the test area comprises sea and topography below $100 \mathrm{~m}$. More details of the geological and geophysical characteristics of the test area can be found, e.g., in Sildvee \& Vaher (1995).

\section{EARTH GRAVITY FIELD MODELS}

\section{Spherical harmonic representation}

As already noted, the Earth's gravitational potential can be expressed in terms of an infinite series of spherical harmonics outside the attracting masses of the Earth. The spectral decomposition is useful for large-scale studies of the gravity field and its relations to density anomalies, ocean currents, Moho depth, Earth magnetism, temperature, and heat flux. Such phenomena may be treated as a wavelike surface built up by superimposing on each other a great number of waves of different wavelengths. Certain gravity field characteristics may appear more clear for some specific harmonic windows than for other parts of the spectra.

Geopotential models are particularly useful for computing gravity anomaly and geoidal heights, which can be represented by a sum of a selected number of degree variances of different wavelengths in the spectral harmonic representation. Free-air anomaly is defined as the difference between the actual gravity (measured on the ground) and the normal gravity $\gamma$, whereas the latter is related to the normal height $H$ (counted from the reference ellipsoid) of the survey point. A gravity anomaly has the physical dimension of acceleration and is commonly expressed in the CGS unit milligal $\left(1 \mathrm{mGal}=10^{-5} \mathrm{~ms}^{-2}\right)$. The free-air anomaly $\Delta g$ can be calculated from the geopotential model by the series (cf. Heiskanen \& Moritz 1967, Ch. 2) 


$$
\Delta g(r, \theta, \lambda)=\frac{G M}{a^{2}} \sum_{n=2}^{n_{\max }}\left(\frac{a}{r}\right)^{n+2}(n-1) \sum_{m=0}^{n}\left\{C_{n m} \cos m \lambda+S_{n m} \sin m \lambda\right\} P_{n m}(\cos \theta),
$$

and geoidal height (in units of length) by

$$
N(r, \theta, \lambda)=\frac{G M}{a \gamma} \sum_{n=2}^{n_{\max }}\left(\frac{a}{r}\right)^{n+1} \sum_{m=0}^{n}\left\{C_{n m} \cos m \lambda+S_{n m} \sin m \lambda\right\} P_{n m}(\cos \theta),
$$

where $C_{n m}, S_{n m}$ are fully normalized spherical harmonic coefficients, of degree $n$ and order $m ;(r, \theta, \lambda)$ are geocentric radius, spherical co-latitude, and longitude of the computational point, respectively; $P_{n m}$ is fully normalized associated Legendre functions, and $G M$ is an adopted gravity mass constant. It should be noted that recent models utilize $G M=398600.4415 \mathrm{~km}^{3} \mathrm{~s}^{-2}$. The coefficients $C_{n m}, S_{n m}$ represent the well-known disturbing potential, which is obtained by subtracting the normal gravity potential of the geodetic reference ellipsoid from the actual gravity potential. The coefficients are related to equatorial radius $a$ of the Earth ellipsoid, whereas up to date, the best estimated value for $a=6378136.3 \mathrm{~m}$. Even though the GGM-derived anomalies are valid on the bounding sphere (with radius $a), \Delta g$ and $N$ can be more or less safely computed inside this sphere, as long as the evaluation point remains outside the topographic masses. In the numerical investigations of this study the gravity field quantities are related to sea level. The application of Eqs. (1) and (2) requires the disturbing potential to be harmonic in this boundary surface, implying that the topographic and atmospheric masses above sea level need to be mathematically reduced inside the geoid or completely removed. As emphasized in Sjöberg (1996, 2001), the influence of the topographic and atmospheric masses could be accounted for separately, and thereafter converted into a geoid model directly. In the computation of the spectral windows of different GGMs this allows us to assume that a geopotential model is a "correct" representation of the gravity field all way down to the geoid's surface. Eventually, the possible consequence of this approximation is almost the same for all GGMs under investigation. In the comparisons this effect will be largely reduced without affecting the objectives of the present study.

Caused by irregularities in mass distributions inside the Earth the geoidal heights undulate with respect to the geocentric reference ellipsoid, e.g., Geodetic Reference System GRS-80. Note also that the series in Eqs. (1) and (2) exclude the zero- and first-degree terms. As is customary in geodesy, the mass of the reference ellipsoid is chosen to be equal to the mass of the Earth, and the origin of the reference ellipsoid is placed at Earth's gravity centre. In this way the zeroand first-degree harmonics vanish. More details and related formulas can be found in any geodetic textbook (see, e.g., Heiskanen \& Moritz 1967). Importantly, the spatial wavelength and resolution of the GGM-derived gravity field parameters 
are directly linked to the harmonic degree $n$ of the geopotential model. By convention, the wavelength is approximately the planet's circumference divided by the degree, i.e., $\lambda=2 \pi a / n(\lambda \approx 40000 / n$, in $\mathrm{km})$, whereas $\lambda / 2$ is the spatial resolution.

Prior to the "space era" the geoid was poorly resolved from land surveying efforts and gravity mapping. New developments and advancements in gravity field determination from tracking of artificial satellites have taken place in the past few decades. Generally, the motion of a satellite is perturbed by various forces. By studying the satellite orbit perturbations the characteristics of the gravity field can be recovered. In the compilation of a GGM, the contribution from the artificial Earth satellites, in particular the long-wavelength information of the Earth's gravity field, becomes especially important. However, only broad geophysical features of the Earth's structure could be detected from the tracking of the satellites. Improvements to the Earth's gravity models at medium and short wavelengths should come from the use of terrestrial, marine, or airborne gravity surveys - also of varying epoch, quality, and geographic coverage. The weighting of the various data types in the development of the potential coefficient models is a delicate task. The accuracy of such models, at the higher degrees, is dependent on the geographic coverage of gravity data that go into the solution. As the coverage improves, so will the model. A practical difference between $\Delta g$ and $N$ should be outlined. The signal-to-noise ratio of the geoidal heights is greater at long wavelengths than for gravity anomalies, the reverse being generally true at short wavelengths. In consequence, the two datasets often provide complementary constraints on geophysical models.

\section{The Earth Geopotential Model EGM96}

In the past 40 years, many geopotential models have been estimated. For an extensive description of the existing models we refer to Bouman (2000) and references therein. It is commonly admitted that EGM96 (Lemoine et al. 1998) is of the best global accuracy among the models of the past decade. The EGM96 harmonic coefficients $\left(C_{n m}\right.$ and $\left.S_{n m}\right)$ are complete to degree and order 360 . Geoidal heights derived from EGM96 are claimed to be accurate to $1 \mathrm{~m}$ worldwide. The EGM96 model is obtained from combining satellite tracking data, surface gravity data, and satellite altimeter measurements. The long-wavelength part of the Earth's gravity field was determined from various tracking measurements of orbiting satellites. The spatial resolution of the "satellite-only" solution is limited to about $600-700 \mathrm{~km}$, implying the highest harmonics degree as of 35 . The data in the EGM96 solution are of considerably varying vintage and quality, and of incomplete geographical coverage. Nevertheless, the EGM96 model represents a significant improvement over earlier models due to the release of new gravity data from formerly classified sources, as well as improved satellite tracking data. 


\section{The GRACE Gravity Model GGM01}

In the years 2000 and 2002, two dedicated gravity field missions started to operate. These missions are: CHAllenging Minisatellite Payload (CHAMP) for geoscientific and atmospheric research, managed by the GeoForschungsZentrum Potsdam (GFZ); and Gravity Recovery and Climate Experiment (GRACE), initiated by the National Aeronautics and Space Administration (NASA). The main goal of those missions is the provision of the static and time variable (e.g., due to ocean currents and seasonal mass redistribution) gravity field with unprecedented accuracy. In this respect, GRACE twin-satellites are outstandingly useful.

The GRACE tracking data serve as the basis of the new geopotential model GGM01s (www.csr.utexas.edu/grace/gravity), released in July 2003 by the Centre for Space Research at the University of Texas, a group led by GRACE principal investigator Dr. B. Tapley. This model employs 111 days of tracking data gathered during April through November 2002. The GGM01s field is developed to degree and order 120, whereas the solution provides full-power results up to about harmonic degree 95. This improvement (recall that the EGM96 satellite-only component is estimated up to degree and order 35) has been possible by the measurement of the inter-satellite range changes on almost polar orbits. Due to the global, homogeneous nature of GRACE data, the resulting geoid errors show no discrimination between land and sea areas, as previous gravity models do. The GRACE group assessed the accuracy of the geoidal heights, implied from GGM01. Naturally, the geoid undulation error is smaller at lower spherical harmonic degrees than at higher degrees. The GGM01s geoid is estimated to be accurate to approximately $2 \mathrm{~cm}$ to degree and order 70 (300 km resolution) and $6 \mathrm{~cm}$ to degree and order 90 (200 km resolution). Furthermore, the GGM01s was combined with the Texas Earth Gravity Model TEG-4 (recent update in Tapley et al. 2003) information equations (created from historical multisatellite tracking data and surface gravity data) to produce a preliminary gravity model GGM01c, complete to degree and order 200.

It should be noted that other models, such as already noted TEG-4 and the EIGEN series of Potsdam GFZ, are also partly utilizing either CHAMP or GRACE data. However, these models are either of poorer resolution or use little GRACE data. Future GRACE gravity models, to be derived from longer time-spans and with improved processing methods, are expected to increase the resolution and accuracy of the GGM even further. In this study the EGM96 and GGM01 models and their discrepancies are evaluated and discussed.

\section{GRAVITY ANOMALY VERSUS GEOIDAL HEIGHTS}

The results of gravity measurements are widely used in geological mapping and exploration for natural resources. On top of this, the data can be used in studying the figure, composition, and structure of the Earth. Generally, the Earth comprises the crust, mantle, and core (finer elements are not distinguished here). 
Consequently, there are two gravitationally significant interfaces (with substantial density jumps) inside the Earth: (1) the core-mantle boundary and (2) the Moho surface, which separates the crust and the mantle. Obviously, the gravity field anomaly measured on the ground surface is very likely a combined result of three-dimensional density variations of a number of the Earth's interior elements. Although this fact makes an interpretation of gravity data difficult without additional geophysical or geological constraints, it does provide important and primary information about the subsurface density structure. Gravity field anomalies are obviously proportional to mass anomalies. For instance, a positive local anomaly indicates a positive density contrast between the source and the surrounding material. Since the density disturbances generate the gravity field anomaly, it is of interest to recover density disturbances from gravity data. For example, a classical problem is to find the density contrast at the Moho surface. This task is usually constrained with some other geophysical information, such as the depth to Moho.

The standard gravity data used in geophysical interpretations, alone or in conjunction with other kinds of data, are gravity anomalies. The accuracy of terrestrially collected gravity anomalies is generally adequate for geophysical interpretation. The geoid, due to its nature, lacks the high-frequency content that is naturally present in the gravity anomaly. Thus, if one is looking for the interpretation of very short-wavelength features - which generally reflect shallow density anomalies - the geoid is not going to be of much help. For instance, the largest gravity anomalies of $\pm 400 \mathrm{mGal}$ occur at sites of island arcs/trench combinations, where volcanism and plate subduction lead to narrow bands of local mass excess or deficiency. However, the sites with the greatest gravity anomalies are not necessarily related to major geoid anomalies.

The satellite-derived geoidal undulations provide new tools required for studying the Earth's interior and the dynamic processes that take place within the Earth. The gravity potential determined from homogeneous orbits of satellites is now of sufficient quality for computing the long-wavelength features of the geoid. Thus the geoidal signal has become a routine information for geophysical interpretations.

Low-degree components of the gravitational potential have fairly straightforward interpretations. The corresponding wavelengths are very long, suggesting that a possible signal source may extend to depths, which commensurate with the wavelength. That is one of the reasons why it is argued that harmonics of degrees 2 and 3 may be related to core-mantle boundary topography, or processes in the lower mantle. Comparison of gravity field characteristics with mantle seismic tomography results indicates an intermediate depth of mass sources (e.g. mantle convection processes), which yield degrees 4-10 geoid anomalies. Components of harmonics between 11 and 35 degrees reflect the influence of Moho depth variations and lateral density anomalies of the crust. And finally, the short-wavelength contribution indicates smaller, near-surface mass anomalies.

It is not an easy task to distinguish between different phenomena. Apparently, the significance and origin of different spectral window contributions remain, however, a point of debate. The causal relationships between geoid anomalies and 
the present state and dynamics of the Earth's interior are rather controversially discussed in geophysical literature; for more details and alternative suggestions see reviews in Lambeck (1988), Vaníček \& Christou (1994), and references therein. It should be emphasized that it is not the scope of this paper to prove or attack the above assumptions, but the present section is meant to provide a general idea about the extension and possible causes of geophysical phenomena influencing also the gravity field parameters.

To summarize this section, it is believed that global features of the geoid are mainly due to mantle convections deep inside the Earth. It could also be concluded that for studies of deep Earth phenomena one should not limit oneself to the use of regional gravity data only, instead it is necessary to involve the gravity field information all over the globe. Regional or local variations in the geoid at smaller magnitude can be associated with the isostatic phenomena, post-glacial rebound, and topographical effects. The geoidal undulations are more favourable candidates for deep Earth studies, whereas gravity anomalies are more sensitive to shallow structures and short-wavelength phenomena.

\section{NUMERICAL INVESTIGATIONS AND DISCUSSION}

The resolution of geopotential models is directly dependent on the maximum harmonic degree of expansion, $n_{\max }$ (see Eqs. (1) and (2)). The higher $n$ is applied, the finer elements of the gravity field can be sensed. However, there is a striking difference in the harmonic degree contributions for the geoid than that for gravity anomaly. Generally, the cumulative sum of the first few degrees in Eq. (2) contribute most to the final geoid height value. In contrast, the summation in Eq. (1) must be extended to one hundred (or more) degrees for gaining about half of the "true" gravity anomaly. To illustrate this phenomenon, $\Delta g$ and $N$ are computed for a site of the largest gravity anomaly over the Baltic Sea. This point is located just off the coast, near the upper reaches of the Gulf of Bothnia. Its geographical latitude and longitude are $\varphi=63^{\circ}$ and $\lambda=20.5^{\circ}$, respectively. The "true" values for $\Delta g$ and $N$ are calculated according to methods and data described in Ellmann (2001) (also in Ellmann 2002). The results are reviewed in Table 1.

Table 1. Cumulative sum of gravity field parameters at different upper limits ( $\left.n_{\max }\right)$ of spherical harmonic coefficients of the geopotential models GGM01 and EGM96

\begin{tabular}{l|c|c|c|c}
\hline $\begin{array}{l}\text { The site with geographical latitude } \\
\varphi=63^{\circ} \text { and longitude } \lambda=20.5^{\circ}\end{array}$ & $\begin{array}{c}\text { "True" } \\
\text { value }\end{array}$ & $\begin{array}{c}n_{\max }=360 \\
\text { (EGM96) }\end{array}$ & $\begin{array}{c}n_{\max }=200 \\
\text { (GGM01c) }\end{array}$ & $\begin{array}{c}n_{\max }=95 \\
\text { (GGM01s) }\end{array}$ \\
\hline $\begin{array}{l}\text { Gravity anomaly, Eq. (1), mGal/ } \\
\text { Deviation from the "true" value, } \%\end{array}$ & $-80.3 /-$ & $-74.6 / 7.1$ & $-51.0 / 36.5$ & $-35.0 / 56.4$ \\
$\begin{array}{l}\text { Geoidal height, Eq. (2), } \mathrm{m} / \\
\text { Deviation from the "true" value, } \%\end{array}$ & $18.8 /-$ & $19.3 / 2.7$ & $19.8 / 5.3$ & $20.7 / 10.1$ \\
\end{tabular}


A similar behaviour of the cumulative contribution of gravity field parameters can be observed at any point in the Baltic Sea region. This simple test proves that the resolution of current geopotential models is useful for the studies of geophysical phenomena of long-wavelength nature, but not when studying the finer details of the Earth's composition. Consequently, the focus of the present study is on the applications of geoidal heights, i.e., long-wavelength characteristics of the gravity field. We start with spectral comparison of the GGM01 and EGM96 geoid models. Further on, their quality is assessed by exploiting some high-precision GPS-levelling data and by the computations of a high-resolution geoid model.

\section{Comparisons of different spectral windows of the geoid models}

Several sets of geoidal heights in $1^{\circ} \times 1^{\circ}$ grids were computed for the study area by Eq. (2). Each of those grids utilizes either a different geopotential model (GGM01s or EGM96) or different degrees of expansion $n$. Three values of $n$ are chosen for numerical investigations - 10, 35, and 95. This selection is not random; recall that 35 and 95 are the upper degrees of full-power "satellite-only" solutions of EGM96 and GGM01s, respectively. The first 10 degrees of a geopotential model portray very long-wavelength features of the gravity field, being thus important for deep Earth studies. For the results of an almost similar study in Fennoscandia we refer to Sjöberg et al. (1994a, 1994b), though a different geopotential model and dissimilar limits of the spectral windows were utilized there.

Geophysical phenomena are often studied by inspecting the spectral windows of the geoidal signal, also called the residual geoid. The residual geoid $N_{\mathrm{i} ; \mathrm{j}}$ is obtained by subtracting the low-resolution contribution (extended up to $n=\mathrm{i}$ ) from the one adopting an upper limit $n=\mathrm{j}$, thus $\mathrm{i}<\mathrm{j}$. In other words, we apply either low-pass or high-pass (or both) filtering approaches. Since numerical investigations utilize two different geopotential models, the discrepancies among GGM01s and EGM96 are of natural interest. Discrepancies $\Delta N_{\mathrm{i} ; \mathrm{j}}$ for each spectral window are calculated as

$$
\Delta N_{\mathrm{i} ; \mathrm{j}}=N_{\mathrm{i} ; \mathrm{j}}^{\mathrm{GGM} 01 \mathrm{~s}}-N_{\mathrm{i} ; \mathrm{j}}^{\mathrm{EGM} 96},
$$

where superscripts denote utilized geopotential models. Numerical statistics for selected spectral windows and their discrepancies are presented in Table 2.

The results in Table 2 need to be discussed more explicitly. The long-wavelength contribution of the geoidal height, $N_{2 ; 10}$, is presented in Fig. 2. As expected, the shape and magnitude of $N_{2 ; 10}$ are rather similar to the final geoid model (cf. Fig. 1, and columns 2 and 3 of Table 2). The geoid anomaly plots and the numerical results demonstrate that the range of the geoid height changes, but little, by inclusion of the contribution of harmonic degrees $n>10$. Roughly, the first 10 degrees provide almost $70 \%$ of the final geoid model in the Baltic Sea region. Importantly, the main part of $N_{2 ; 10}$ is contributed by $N_{2 ; 3}$. As already noted, the gravity field features of this spectral window are of global nature. 
Table 2. Numerical statistics for selected spectral windows $\left(N_{\mathrm{i} ; \mathrm{j}}\right)$ of the GGM01s and EGM96 geopotential models. Unit is metre

\begin{tabular}{l|r|r|l|l|l|l|c}
\hline $\begin{array}{c}\text { Contribution } \\
\text { of } N_{\mathrm{i} ; \mathrm{j}} / \\
\text { Discrepancies } \\
\Delta N_{\mathrm{i} ; \mathrm{j}}\end{array}$ & $\begin{array}{c}N_{2 ; 360} \\
\text { (EGM96) }\end{array}$ & $N_{2 ; 10} / \Delta N_{2 ; 10}$ & $N_{2 ; 35} / \Delta N_{2 ; 35}$ & $N_{2 ; 95} / \Delta N_{2 ; 95}$ & $N_{11 ; 35} / \Delta N_{11 ; 35}$ & $N_{36 ; 95} / \Delta N_{36 ; 95}$ & $N_{96 ; 360}$ \\
$($ EGM96)
\end{tabular}

Discrepancies $\Delta N_{\mathrm{i} ; \mathrm{j}}$ for each spectral window are calculated as $\Delta N_{\mathrm{i} ; \mathrm{j}}=N_{\mathrm{i} ; \mathrm{j}}^{\mathrm{GGM} 01 \mathrm{~s}}-N_{\mathrm{i} ; \mathrm{j}}^{\mathrm{EGM} 96}$.

An important finding is that the discrepancies between GGM01s and EGM96 for this spectral window range from 0 to $-6 \mathrm{~cm}$ (see column 3 of Table 2). In the southern part of the study area, i.e. around latitude $54^{\circ}$, the discrepancies are zero but decreasing gradually northwards. The $\Delta N_{2: 10}$ minimum is located at the northernmost edge of the study area. Most likely this is caused by the improved data of the GRACE satellites, which are placed on almost polar orbits. This is also supported by the circumstance that at time of the EGM96 compilation the

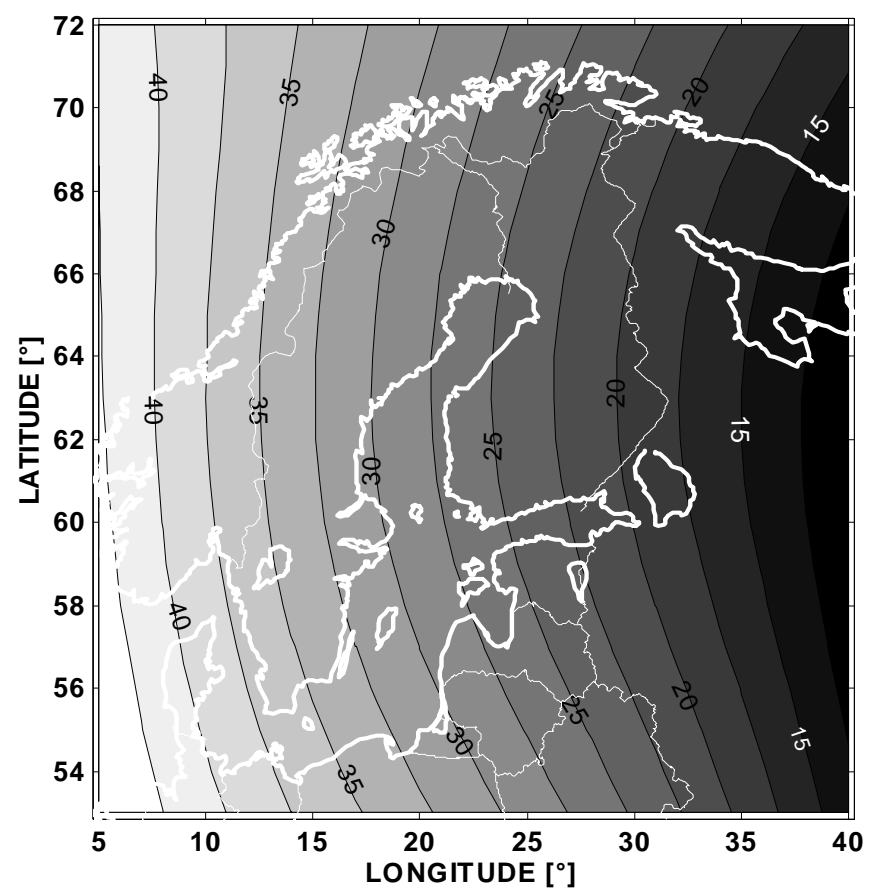

Fig. 2. Long-wavelength contribution of geoidal heights, $N_{2 ; 10}$ (spectral window 2-10). Unit is metre, the contour interval is $2.5 \mathrm{~m}$. 
sub-polar latitudes were rather poorly covered by satellite tracking data. For other spectral windows the tilt-like discrepancy trend is visually not detectable. The discrepancies between GGM01s and EGM96 geoid grids at harmonic degree 95, $\Delta N_{2 ; 95}$, are portrayed in Fig. 3. The amplitude of $\Delta N_{2 ; 95}$ may vary several decimetres, whereas the two largest positive discrepancies are located beneath the highest mountains in Norway and at the shores of the Gulf of Riga in the Baltic Sea. However, the mean of all discrepancies in the whole study area remains almost the same, $-2 \mathrm{~cm}$ (see Table 2, columns 3-5 of row 3). Obviously, this negative average is primarily stemming from the long-wavelength $\Delta N_{2 ; 10}$. Note also that for high-pass spectral windows (i.e., without $N_{2 ; 10}$ contribution) the mean of discrepancies has changed. It could be supposed thus that GRACE measurements have most likely improved the long-wavelength gravity field data in sub-polar latitudes.

The contribution of the spectral window $N_{11 ; 35}$ is often considered in the Moho surface and post-glacial land uplift studies. Generally, variations of the Moho depth and density contrast may have large effects on the gravity field. For instance, the general patterns of the European gravity field are explained by the variations of the Moho depth in Europe, and especially clearly this correlation can be observed in the example of the Swiss geoid model (Marti forthcoming). The Moho depth model is usually compiled from a number of deep seismic sounding profile data;

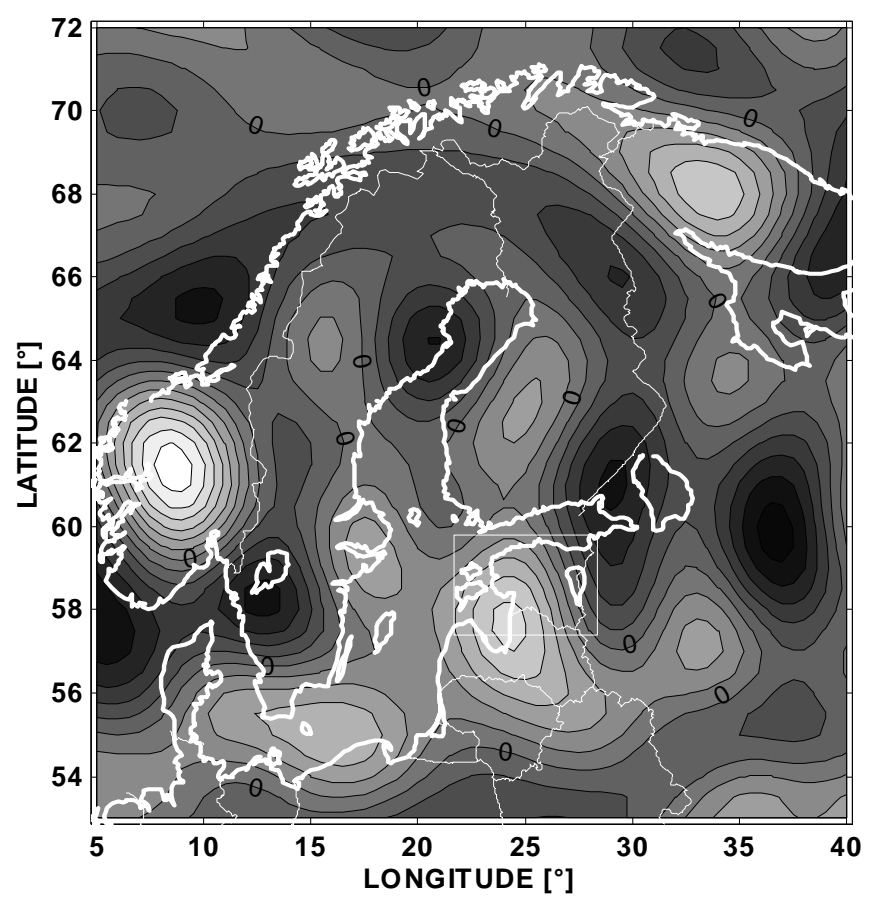

Fig. 3. Discrepancies between spectral windows 2-95 of the GGM01 and EGM96 geopotential models, $\Delta N_{2 ; 95}$. Regional maximum is $+0.8 \mathrm{~m}$ (brightest region) and the minimum is $-0.6 \mathrm{~m}$ (darkest region), the contour interval is $0.10 \mathrm{~m}$. 
a recent update for Fennoscandia can be found in Luosto (1997). The residual geoid, $N_{11 ; 35}$, varies in the study area from -7.7 to $+6.2 \mathrm{~m}$ (see Fig. 4 ). Note also the negative mean of $N_{11 ; 35}$ (cf. Table 2, row 3 of column 6). Similarly to some previous studies a large geoidal depression of about $8 \mathrm{~m}$ was detected in the central part of the Baltic Sea region. Since the crustal variations produce geoidal anomalies with similar wavelengths as those of land uplift, it is very difficult to distinguish between respective phenomena in the resulting geoid signal. Various conclusions have been reached to explain this effect, however, residual geoid anomaly is more often assumed to be due to deglaciation. Many authors have studied causal relationships between the gravity field parameters and the effects of the crustal structure, Moho variations, and post-glacial rebound in Fennoscandia. For instance, Anderson (1984) found a strong correlation between the Moho depth and the geoid features of Fennoscandia. A later study by Marquart (1989) concluded that the geoid depression for deglaciation is hardly detectable, supporting thus the results of Anderson. Conversely, the study series by Sjöberg et al. (1994a, 1994b) indicates that the Moho depth variations contribute only little to gravity field features in Fennoscandia. They applied rigorous integral formulas along with an updated Moho map and more recent geopotential models (OSU 89B and OSU 91A). The study results revealed that the amount of geoidal depression that may be attributed to the post-glacial rebound is about $6 \mathrm{~m}$ in the centre of the land uplift area.

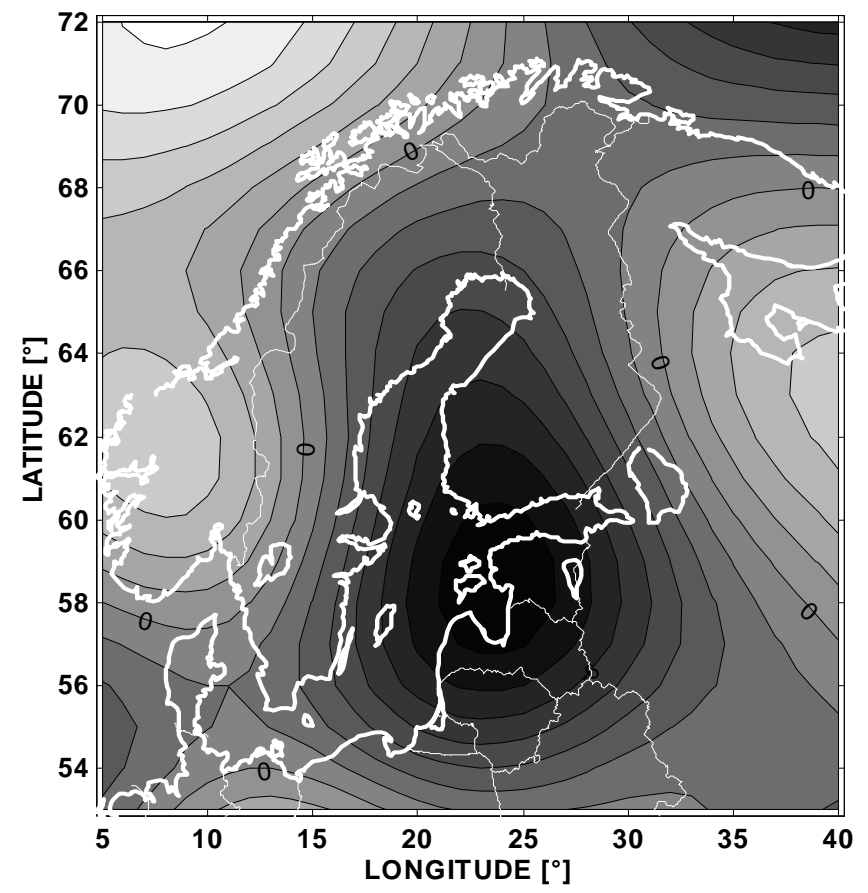

Fig. 4. Medium-wavelength contribution of geoidal heights, $N_{11 ; 35}$ (spectral window 11-35). Regional maximum is $+6.2 \mathrm{~m}$ (brightest region) and the minimum is $-7.7 \mathrm{~m}$ (darkest region), the contour interval is $1 \mathrm{~m}$. Note the geoidal depression of about $8 \mathrm{~m}$ in the study area centre. 
Indeed, there is no visual evidence of correlation between residual geoid $N_{11: 35}$ in Fig. 4 and Moho depth features in the region. Due to the depth of the Moho surface (in the study area varying from 30 to $60 \mathrm{~km}$ ), its possible impact on the geoid model is expected to be rather smooth. The depression of $N_{11 ; 35}$ more or less coincides with the present land uplift area in Fennoscandia. This phenomenon may thus overshadow the possible effect of Moho topography variations. It is notable, however, that the extreme of the depression is not exactly coincident with the site of the land uplift maximum (at $\varphi \approx 65^{\circ}$ and $\lambda \approx 22^{\circ}$ ). Instead, the maximum depression is shifted southwards. Interestingly, it is very close to the local Moho depth extreme $(55 \mathrm{~km})$ beneath the Gulf of Riga (situated at $\varphi \approx 58^{\circ}$ and $\lambda \approx 24^{\circ}$, cf. Luosto 1997). Most likely this agreement is random, since at the location of the largest regional Moho depth $(60 \mathrm{~km})$ in eastern Finland $\left(\varphi \approx 62.5^{\circ}\right.$ and $\lambda \approx 28^{\circ}$, cf. ibid.) such a depression of the residual geoid is not observable. To conclude this discussion, the geoidal depression of $N_{11 ; 35}$ is mainly associated with the post-glacial rebound, and may also be influenced by the structure of the crust and subcrustal processes (Kakkuri \& Wang 1998). It should be noted, however, that the residual geoid plot might slightly change when choosing different upper or lower limits of the spectral window.

The discrepancies $\Delta N_{11: 35}$ vary from -0.3 to $+0.4 \mathrm{~m}$ (see Fig. 5). The discrepancies are rather significant, the maximum $\Delta N_{11: 35}$ is situated west of Estonia,

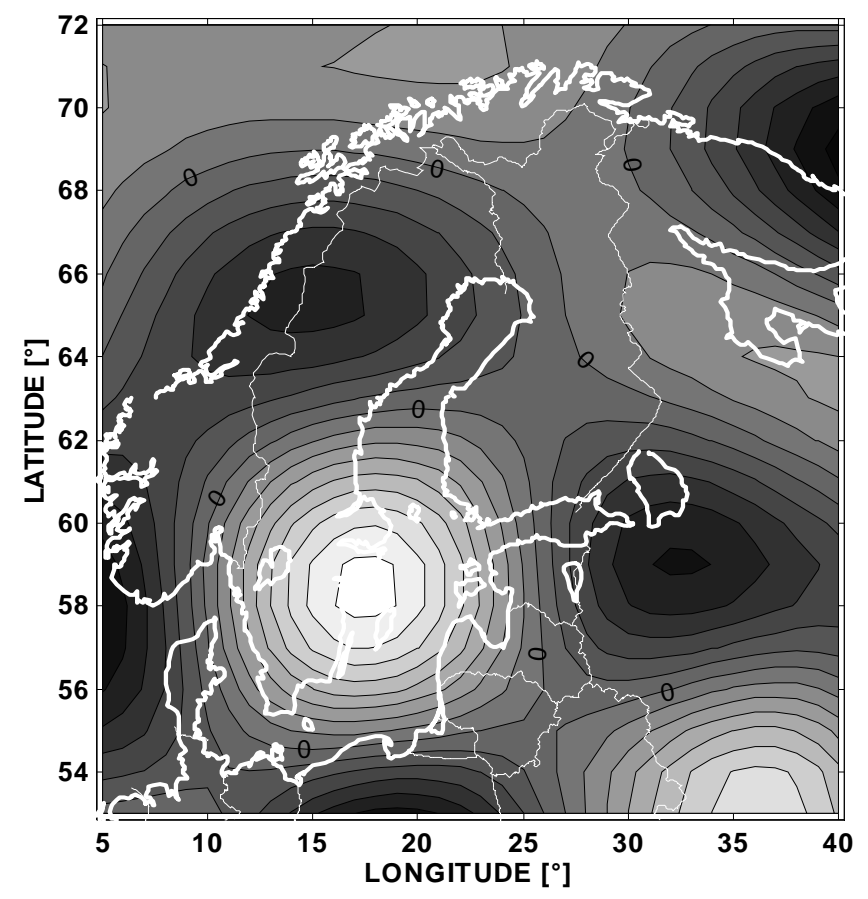

Fig. 5. Discrepancies between the GGM01 and EGM96 geopotential models, $\Delta N_{11 ; 35}$ (spectral window 11-35). Regional maximum is $+0.4 \mathrm{~m}$ (brightest region) and the minimum is $-0.3 \mathrm{~m}$ (darkest region), the contour interval is $0.05 \mathrm{~m}$. 
near the east coast of Sweden. Since the first 35 spherical harmonic degrees of EGM96 utilize historical and insufficiently covered satellite tracking data, this may indicate enhancements from the GRACE measurements. Note that the geographical distribution and appearance of $\Delta N_{11 ; 35}$ highs and lows are rather random, without any remarkable systematic offset for this spectral window (see Table 2, row 3 , column 6 ).

The contribution of the spectral window $N_{36 ; 95}$ ranges within +3.3 to $-3.6 \mathrm{~m}$ (see Fig. 6). Apparently, the inclusion of higher-degree coefficients adds more details into the gravity field.

Over the Baltic Sea the negative contribution of $N_{36,95}$ prevails, however its regional mean is almost zero (see Table 2, column 7). Compared to $\Delta N_{11 ; 35}$, the magnitude of the discrepancies $\Delta N_{36 ; 95}$ is two times larger, ranging from -0.67 to $+0.84 \mathrm{~m}$. The causes of the discrepancies $\Delta N_{36 ; 95}$ remain uncertain. Recall that higher than 35 degree of EGM96 harmonics were compiled from combining satellite tracking, satellite altimetry, and terrestrial gravity datasets. The study area is gravimetrically well studied, thus the terrestrial gravity data incorporated into EGM96 may be more accurate than the gravity field parameters derived from GGM01s.

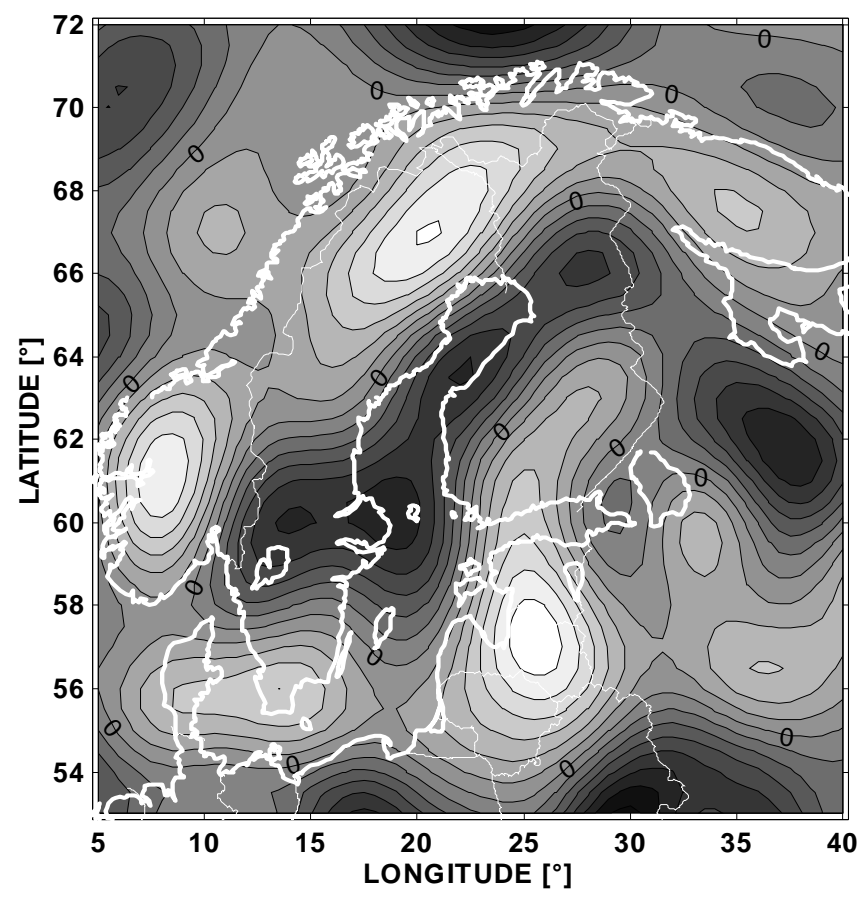

Fig. 6. The contribution of the residual geoid $N_{36 ; 95}$ (spectral window 36-95). Regional maximum is $+3.3 \mathrm{~m}$ (brightest region) and the minimum is $-3.6 \mathrm{~m}$ (darkest region), the contour interval is $0.5 \mathrm{~m}$. 
There are several corrections, which should be counted in the geoid computation process (see, e.g., Sjöberg 1996, 2001 and references therein). In particular, the influence of the atmospheric and topographic masses, and the effect of the Earth's ellipticity should be considered. It should be noted that the corrections are counted in the computations of the high-precision Estonian geoid (see below).

According to a study by Ellmann (2001, Ch. 5.5), the topographic effect on the geoid is larger than other effects in the study area. The topographic effect is always a negative quantity, and as expected, the higher the topography, the greater this effect. The topography of the study area is not uniform. The eastern part of the Baltic Sea region is a large flat area with a height of only a few hundred metres, whereas a mountain range is situated along the Norwegian coast. The topographic effect is little above the sea surface and coastal areas, whereas it may reach up to $0.3 \mathrm{~m}$ (cf. Ellmann $\&$ Sjöberg 2002) at the location of the highest topographic masses (up to $2.4 \mathrm{~km}$ ) in southwest Norway $\left(\varphi \approx 61.6^{\circ}\right.$ and $\lambda \approx 8^{\circ}$ ). Interestingly, the largest $(0.8 \mathrm{~m})$ discrepancy $\Delta N_{36 ; 95}$ is related to the same site (cf. Fig. 7). The discrepancies of that size may be caused by the different methods of the treatment (if treated at all) of topographic effects when compiling the geopotential models under study. The topographic effect may thus be aliased into

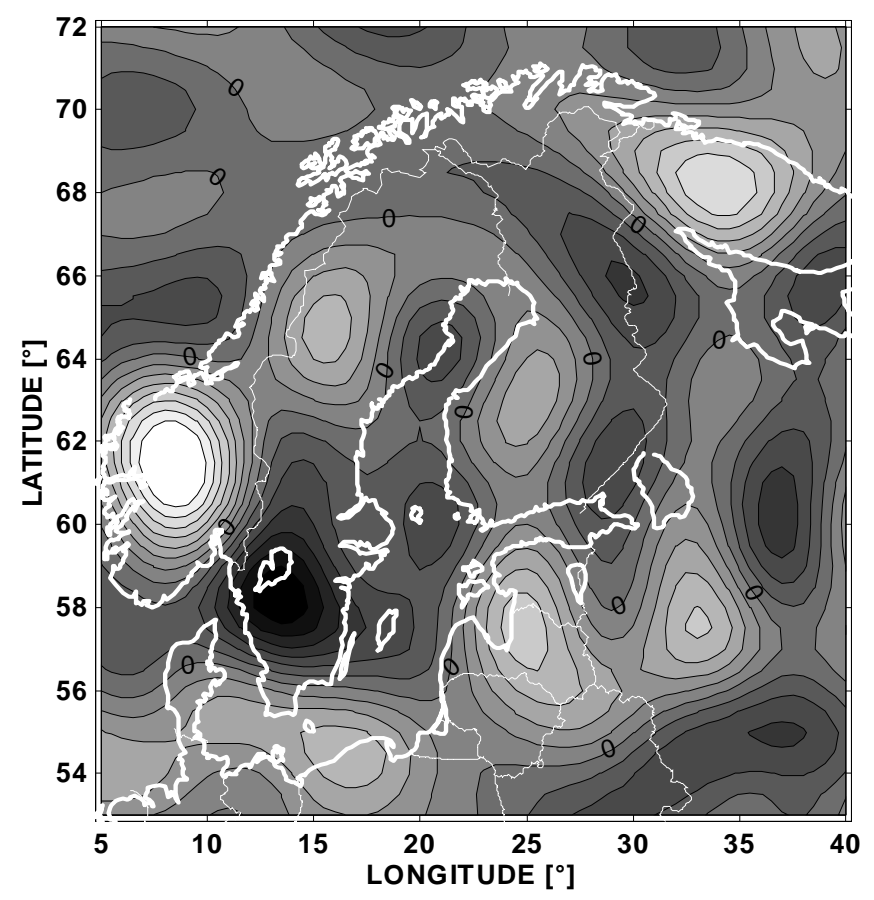

Fig. 7. Discrepancies between the GGM01s and EGM96 geopotential models, $\Delta N_{36 ; 95}$ (spectral window 36-95). Regional maximum is $+0.8 \mathrm{~m}$ (brightest region) and the minimum is $-0.7 \mathrm{~m}$ (darkest region), the contour interval is $0.1 \mathrm{~m}$. 
discrepancies of this spectral window. Since most of the study area comprises sea or lowland, possible deviations in the topographic effect treatment methodology do not affect the remaining comparisons of the present study. Further studies may be necessary for detecting which geopotential model reflects better the features of this spectral window in the study area.

One should note that the geopotential model EGM96 may carry significant geoid undulation information between degrees 95 and 360. In the study area, this contribution ranges from -3.1 to $+2.6 \mathrm{~m}$ (see Table 2). However, on a regional average the contribution of $N_{96: 360}$ is almost zero.

Combined geopotential models are proving their value in many applications. The accuracy of combined models, such as EGM96 and GGM01c, at the higher degrees is quite dependent on geographical coverage of gravity data that go into the solution. Since the main scope of the present study is to assess the enhancements of the new satellite gravity mission, comparisons for other spectral windows are not produced. To sum up this section, the range of discrepancies between GGM01s and EGM96 may reach several decimetres in the study area. However, different results of geoid modelling can be expected in different regions. One may naturally ask, which model under study is best suited for a region of interest, or in other words, which one corresponds better to the ground data. For the assessment of geoid models the comparison with the Global Positioning System (GPS) and levelling datasets is very useful. The results of relevant tests are presented in the next subsection.

\section{Comparison with GPS-levelling data}

As is well known, the intercomparison of a geoid model, GPS-derived geodetic heights, and spirit-levelled (normal or orthometric) heights at discrete points gives a reasonable indication of the geoid model accuracy. The validation of the EGM96 and GGM01 models relays on two sets of high-precision geodetic points - one in Estonia, and another one in Sweden. The average distance between 26 evenly distributed Estonian control points (for their locations see Fig. 8) is $50 \mathrm{~km}$, whereas the average distance between 21 nationwide Swedish points (indicated in Fig. 1) is $150 \mathrm{~km}$. For all points geodetic heights from GPS-measurements as well as levelling heights are available. The geodetic coordinates of both sets are related to the respective national realization of the new European Terrestrial Reference System ETRS-89. On the contrary, the spirit-levelled normal heights refer to different vertical datums. The Baltic Height System 1977 is used in Estonia, whereas the Swedish national height system is RH70.

Historically, the zero-point of a height datum for a country is based on averaging the sea level records over some period at one or more tide-gauge stations. For instance, Estonian height networks are currently related to Kronstadt tide-gauge (in the vicinity of St. Petersburg, $\varphi \approx 60^{\circ}$ and $\lambda \approx 30^{\circ}$ ), whereas the height systems of many West European countries, including Sweden, are tied to the sea level observations at Amsterdam tide-gauge (located at $\varphi \approx 52.5^{\circ}$ and $\lambda \approx 5^{\circ}$ ). 
According to several sources (see, e.g., Ihde et al. 2000) the difference between two datums is approximately $15 \mathrm{~cm}$. Even though the data at these tide-gauges are acquired during different time spans, this is a direct evidence that mean sea level at the eastern shore of the Baltic Sea is higher than the one at the North Sea. Furthermore, offsets between national datums occur due to post-glacial land uplift, and most importantly, a chosen time epoch for the network adjustment may vary significantly. Subsequently, a local height system is not necessarily coincident with the global geoid model. Recall also that data all over the globe are integrated for the compilation of a combined GGM, thus, datum inconsistencies are inherited into a solution for geopotential coefficients.

From that point of view it is preferable to use the control points whose quality is assured and which are related to the same reference system. This suggests thus separate verifications for Estonia and Sweden. At Estonian points, the combined error of GPS-derived and spirit-levelled heights cannot be greater than $2-3 \mathrm{~cm}$. For Sweden, the stations of the GPS reference network SWEPOS are utilized. The heights of SWEPOS stations are retrieved from the Swedish National Land Survey ftp-server (ftp://swepos.lmv.lm.se/swepos/Koord_Hojd). Consequently, for this set the effects due to land uplift of some recent years are disregarded. Even though land uplift rates in Sweden are the largest (reaching up to $1 \mathrm{~cm} /$ year) in the study area, it is expected that the combined GPS-levelling heighting error at the control points is less than $5 \mathrm{~cm}$. As it will be shown below, this value does not affect the scope of present exercise, and is thus negligible. The adopted assumption is supported by the circumstance that the limitations related to the models resolution certainly override the land uplift effect of a few years. It should be noted that the combined topographic effect in Estonia is almost constantly $-2 \mathrm{~cm}$, whereas at the locations of SWEPOS stations it does not exceed $-7 \mathrm{~cm}$; for more details see Ellmann \& Sjöberg (2002). At most of Estonian and Swedish GPS-levelling points, however, the topographic correction is similar and can be thus omitted in further comparisons.

A nationwide set of GPS-levelling points forms the "geometric geoid model", which here is considered as a practical realization of the national height system. A geometric geoid height, $N_{\text {geom }}$, is obtained by algebraically subtracting the levelling height $H$ from a GPS-derived height $h$, i.e. $N_{\text {geom }} \cong h-H$.

The EGM96, GGM01c, and GGM01s models are to be validated with the GPS-levelling points. The models are developed up to $n_{\max }$ of 360 (resolution $55 \mathrm{~km}$ ), 200 (resolution $100 \mathrm{~km}$ ), and 120 (resolution $167 \mathrm{~km}$ ), respectively. Each model is utilized to calculate the geoidal heights $N$ of the control points by Eq. (2). Comparison of a GGM-derived and the geometrical geoid models at discrete points gives a good indication about the compatibility of the pairs of geoid models. The numerical statistics of the comparisons of respective pairs of geoid models are presented in Table 3.

The magnitude of exposed differences between geometric and GGM-derived geoid models, $\delta N=N_{\text {geom }}-N$, range from +0.8 to $-1.7 \mathrm{~m}$. Generally, the greater is $n_{\max }$, the lesser are the deviations. The satellite-only model GGM01s has the 
Table 3. Numerical statistics of the comparison between the geoid models and national GPSlevelling points. Unit is metre

\begin{tabular}{|c|c|c|c|c|c|c|c|}
\hline \multirow{2}{*}{ Model } & \multirow{2}{*}{ Country } & \multicolumn{3}{|c|}{ Difference $\delta N=N_{\text {geom }}-N$} & \multicolumn{3}{|c|}{ Post-fit residuals } \\
\hline & & Min & $\operatorname{Max}$ & Mean & Min & $\operatorname{Max}$ & RMS \\
\hline EGM96 & Estonia (26 points) & -0.78 & +0.26 & -0.21 & -0.39 & +0.26 & 0.14 \\
\hline$\left(n_{\max }=360\right)$ & Sweden ( 21 points) & -0.97 & -0.30 & -0.54 & -0.40 & +0.23 & 0.13 \\
\hline GGM01c & Estonia (26 points) & -0.84 & -0.10 & -0.40 & -0.44 & +0.35 & 0.16 \\
\hline$\left(n_{\max }=200\right)$ & Sweden (21 points) & -1.45 & -0.01 & -0.48 & -0.46 & +0.36 & 0.20 \\
\hline GGM01s & Estonia (26 points) & -0.87 & +0.82 & -0.15 & -0.73 & +0.68 & 0.40 \\
\hline$\left(n_{\max }=120\right)$ & Sweden (21 points) & -1.73 & +0.64 & -0.46 & -0.99 & +1.40 & 0.60 \\
\hline EST-01 & & -0.51 & -0.19 & -0.31 & -0.07 & +0.05 & 0.030 \\
\hline $\begin{array}{l}\text { EST-03 } \\
1.5^{\prime} \times 3^{\prime} \text { grid }\end{array}$ & Estonia (26 points) & -0.49 & -0.30 & -0.39 & -0.08 & +0.05 & 0.031 \\
\hline
\end{tabular}

A geometric geoid height, $N_{\text {geom }}$, is obtained by algebraically subtracting the levelling height from a GPS-derived height. The geoidal heights $N$ at the GPS-levelling points are computed from the geopotential models (EGM96, GGM01c or GGM01s) at their upper limits $\left(n_{\max }\right)$, or by interpolation from the closest grid points of the high-resolution geoid models (EST-01 or EST-03).

largest disagreements, which can be explained by rather coarse spatial resolution of the model. A remarkable finding is that for all three models the negative means of differences are detected, revealing that the national height systems are in average lower than a GGM-geoid. Further on, the Swedish GPS-levelling geoid appears to be "lower" than the one for Estonia. This is in good agreement with the direct results of the levelling $(\sim 15 \mathrm{~cm}$, see above) between East and West European vertical datums. Intuitively, future high-resolution and more accurate global geoid models (can be treated as a world height system) create tools for unification of national height systems all over the globe. Discussion of unification of regional datums along with numerical verifications can be found, e.g., in Pan \& Sjöberg (1998) and Ardalan et al. (2002). The interest in unification of different national datums is twofold. It allows introducing corrections to the national gravity data, in order to relate them into a common global gravimetric reference frame. The more consistent data thereafter create preconditions for the further improvement of a GGM. Literally, one goes through an iterative process.

As already noted, the comparisons of the GGM and the national GPS-levelling data may be affected by systematic effects (e.g., due to land uplift) and datum inconsistencies. Now we attempt to minimize the offsets (i.e., vertical offset and eventual tilt) between global and regional (geometrical) geoid models by introducing a four-parameter polynomial fit. The same sets of GPS-levelling 
points are used for definition of the transformation parameters among the pairs of geoid models. Thereafter, these parameters were applied for fitting the GGMderived geoid models with the GPS-levelling points. The numerical statistics of fitting are presented in Table 3. A root mean square error of post-fitting residuals at Estonian GPS-levelling points of 0.14, 0.16, and $0.40 \mathrm{~m}$ were achieved for EGM96, GGM01c, and GGM01s, respectively. Almost the same root mean square values were obtained at the Swedish control points. Note also significantly reduced magnitude of post-fitting residuals. However, the largest post-fitting residuals exceed $\pm 1 \mathrm{~m}$, and are related to GGM01s. This indicates that the resolution of GGM01s is too coarse, preventing the direct use of that model for practical applications.

To sum up, GGM-derived geoid model accuracies at a few decimetre level can be obtained, provided that any datum inconsistencies have been eliminated. However, the resolution of a GGM must be rather high, because the low-resolution models may portray only broad elements of the gravity field.

During the past two decades, an increased need for refined geoid models has been driven by demands of the GPS users. In many positioning, mapping, and exploration applications, conventional spirit levelling is being replaced by orthometric height determination using GPS and the geoid. Recall that at discrete points a traditional height could be obtained by algebraically subtracting the value of the geoidal height from the geodetic height (acquired from GPS observations). Consequently, for the conversion and combination of these fundamentally different height systems, the geoid model must be known to an accuracy comparable to the accuracy of GPS and traditional levelling, i.e., a few centimetres. The results of simple verifications in Table 3 indicate that up-to-date and even future geopotential models cannot be satisfactory for practical height determination. This renders thus the need for more accurate geoid determination methods. The regional improvement of the geoid model accuracy can be reached by utilizing the modified Stokes' formula, which combines local terrestrial data with a GGM. This approach is described in the next subsection.

\section{Computation of the Estonian geoid model by the modified Stokes' formula}

Stokes' formula, published already in 1849 , remains one of the most important formulas of physical geodesy. This formula enables the determination of the separation $N$ between the geoid and geocentric reference ellipsoid from the global coverage of the gravity anomalies $\Delta g$ :

$$
N=\frac{R}{4 \pi \gamma} \iint_{\sigma} S(\psi) \Delta g d \sigma,
$$

where $R$ is the mean Earth's radius, $\gamma$ is normal gravity on the reference ellipsoid, $\psi$ is geocentric angle, the formula of the Stokes function, $S(\psi)$, can 
be found in most geodetic textbooks, and $d \sigma$ is an infinitesimal surface element of the unit sphere $\sigma$. The double integral in Eq. (4) has to be evaluated over the whole Earth. However, in practice the area of integration is usually limited to a spherical cap around the computation point. The lack of a global coverage of gravity data can be compensated by a combination of terrestrial gravity with a GGM, i.e. the long-wavelength geoid contributions would be determined from a GGM and short-wavelength information from terrestrial gravity data. Assuming a cap of integration $\sigma_{0}$ around the computation point, a general estimator $\tilde{N}$ of the geoidal height is provided by two sets of parameters $\left(s_{n}\right.$ and $\left.b_{n}\right)$, and gravity anomalies $\Delta \hat{g}$, inserted into the modified Stokes' formula

$$
\tilde{N}=\frac{R}{4 \pi \gamma} \iint_{\sigma_{0}} S^{L}(\psi) \Delta \hat{g} d \sigma+\frac{R}{2 \gamma} \sum_{n=2}^{M} b_{n} \Delta \hat{g}_{n},
$$

where the anomaly degree estimate, $\Delta \hat{g}_{n}$, can be calculated from a GGM (by Eq. (1)), and the modified Stokes function is expressed by selected parameters $s_{k}$ and in terms of Legendre polynomials $P_{k}(\cos \psi)$

$$
S^{L}(\psi)=S(\psi)-\sum_{k=0}^{L} \frac{2 k+1}{2} s_{k} P_{k}(\cos \psi)
$$

The upper modification limit $M$ is arbitrary, and generally not equal to $L$.

The modification of Stokes' formula, originating with Molodensky et al. (1962), aims to reduce the truncation error that occurs when the area of Stokesian integration is limited to a spherical cap. Over recent decades several modification approaches have been published in the literature, which are summarized and cited in Sjöberg \& Hunegnaw (2000), among others. It should be noted that many of those studies aim at reducing the truncation error only. It is assumed thus that the errors stemming from the geopotential coefficients and measured gravity anomalies are negligible, an assumption which is obviously not true. With access to recent high-degree GGMs, the truncation error loses some of its significance, and the GGM errors become more important. One should also consider the erroneous terrestrial data within the integration area. In contrast, the modification methods proposed by Sjöberg (1984) (with later modifications) allow least squares minimization of any error in geoid modelling.

In 2001, the $1.5^{\prime} \times 3^{\prime}$ grid of the Estonian geoid model EST-01 was computed by the least squares modification of Stokes' formula (Ellmann 2001, also in Ellmann 2002). In this approach, the modification parameters $s_{n}$ and $b_{n}$ vary, depending on the local gravity data quality, the chosen radius of integration, and the characteristics of the used GGM. The EGM96 model was utilized in EST-01 computations. The modification coefficients, $s_{n}$, are determined in the least squares sense by solving the linear system of equations as discussed in Sjöberg (1984). The least squares modification coefficients $s_{n}=b_{n}$ were estimated 
from the following initial conditions: (1) degree of modification $M=L=360$, (2) terrestrial anomaly variance $9 \mathrm{mGal}^{2}$ (the correlation length as of $0.1^{\circ}$ assumed), (3) integration cap radii $2^{\circ}$ (approx. $220 \mathrm{~km}$ ).

Since the aim of the present study is to evaluate the new geopotential model, it would be of interest to examine the effect of GGM01s on the regional geoid computations. The gravimetric geoid model for Estonia was computed anew. Instead of the EGM96 model, GGM01s is now utilized as an underlying model. Exactly the same computational setup was applied, including also the same grid of free-air gravity anomalies. The interested reader is referred to Ellmann (2001), also Ellmann (2002), for detailed description of initial data, gridding procedures, and formulas.

Since the underlying model has been changed, a new set of least squares modification parameters was computed. The initial conditions for new least squares parameters are summarized as follows: (1) degree of modification $M=L=95$, (2) terrestrial anomaly variance $9 \mathrm{mGal}^{2}$ (the correlation length as of $0.1^{\circ}$ assumed), (3) integration cap radii $2^{\circ}$ (approx. $220 \mathrm{~km}$ ). It should be outlined that the upper limit of modification parameters is now $L=M=95$, instead of $L=M=360$ for EST-01. Recall that the modification degree 95 corresponds to the full power of the GGM01s solution, hence this selection. Inserting into Eq. (5) the $1.5^{\prime} \times 3^{\prime}$ grid of free-air anomalies, the least squares modification coefficients and $\Delta \hat{g}_{n}$ from GGM01s (Eq. (1)) resulted in a new Estonian geoid model. The new gravimetric geoid for Estonia is referred to as EST-03 and is presented in Fig. 8.

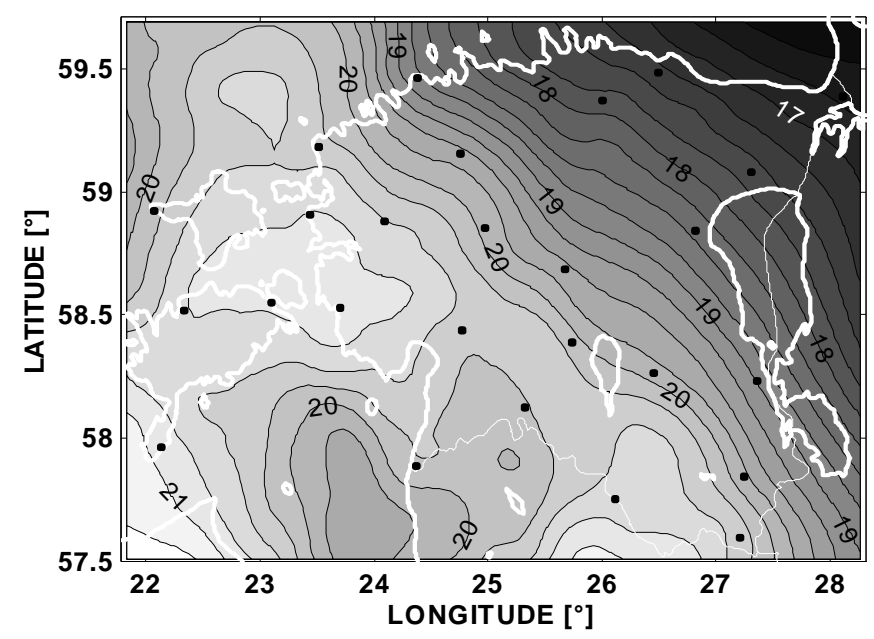

Fig. 8. The Estonian gravimetric geoid model EST-03. The least squares parameters of the modified Stokes' formula account for the characteristics of GGM01s, degrees of modification $L=M=95$, truncation cap $2^{\circ}$, terrestrial anomaly variance $9 \mathrm{mGal}^{2}$. Geoidal heights are given with respect to GRS-80. Unit is metre and the contour interval is $0.25 \mathrm{~m}$. Black dots indicate the location of the GPS-levelling points. 
Generally, the shape of the EST-03 geoid model is similar to the EST-01 (see Ellmann 2002) and earlier models (e.g., Vermeer 1994; Forsberg et al. 1997). The geoidal heights are decreasing towards the northeast, whereas the extremes of 21 and $16 \mathrm{~m}$ are located in the southwest and northeast corners, respectively (the length of this diagonal is $\sim 400 \mathrm{~km}$ ). The geoid is mainly smooth but includes local irregularities in the western and southern parts of the test area. For discussion of possible causes of such gravity field features the interested reader is referred to Ellmann (2002).

The EST-03 and EST-01 geoid models are compared at each grid point. The discrepancies range from -0.03 to $+0.22 \mathrm{~m}$ (a local average is $+0.1 \mathrm{~m}$ ), see Fig. 9. The largest deviations are related to the southwestern part of the test area. It should be noted that very little effect can be caused by the application of different modification degree $L=M=95 \neq 360$. However, a study by Ellmann (2001, Ch. 5.2.3) demonstrates that the contribution from higher than 70 degree geopotential coefficients is rather insignificant in the least squares modification of Stokes' formula. Since the discrepancies in Fig. 9 are of long-wavelength nature, they might be caused by discrepancies between the models EGM96 and GGM01s. We address to Fig. 3, portraying the discrepancies $\Delta N_{2 ; 95}$ which range in the Estonian test area from -0.36 to $+0.53 \mathrm{~m}$ (with the mean of $+0.17 \mathrm{~m}$ ). An obvious correlation between geographical location and magnitude of differences among the pairs of the models EGM96 and GGM01s, and EST-01 and EST-03 can be detected (cf. Figs. 3 and 9).

A question arises as to which geoid model is more useful, EST-01 or EST-03. The same set of 26 GPS-levelling points was used for verification. Here again,

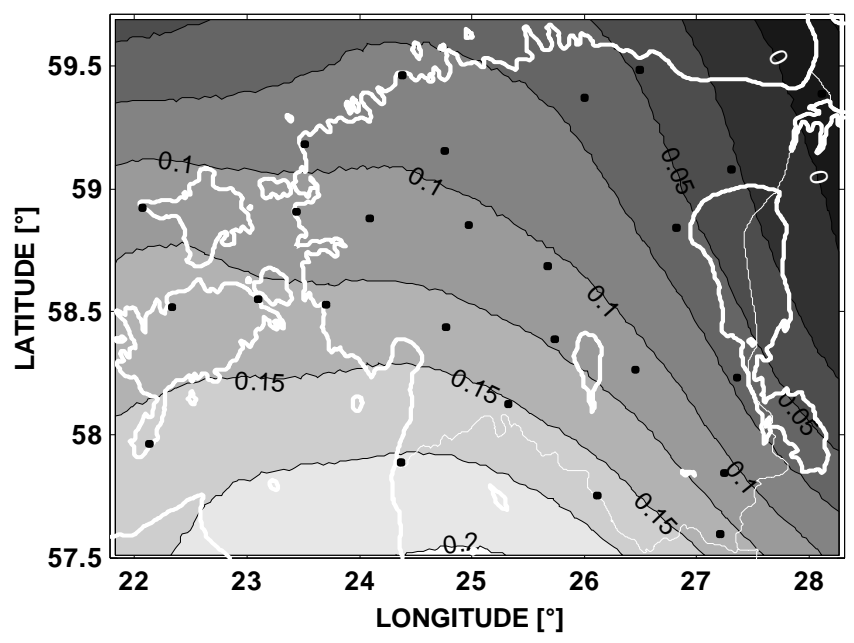

Fig. 9. The differences between the EST-03 and EST-01 geoid models. Note similarities with the central part of Fig. 3. Unit is metre and the contour interval is $0.025 \mathrm{~m}$. Black dots indicate the location of the GPS-levelling points. 
the geometric geoid model is systematically lower than the both EST models, on average around $-0.35 \mathrm{~m}$ (see Table 3 ). A small $\mathrm{SW}-\mathrm{NE}$ oriented tilt $(30 \mathrm{~cm}$ to $350 \mathrm{~km}$ ) between the EST-01 and GPS-levelled heights was detected (Ellmann 2002). This tilt may be an indication of some uncertainties in the EGM96 solution. In contrast, such a tilt is not present when examining differences between the new EST-03 and geometrical geoid models. The models are almost parallel, suggesting a one-dimensional offset. It should be noted that the standard deviation of the pre-fitting parameters, $\delta N$, is 0.078 and $0.044 \mathrm{~m}$, for EST-01 and EST-03, respectively.

Further evaluation of the suitability of the gravimetric geoid models is based on the post-fitting residuals (see Table 3 ). The four transformation parameters between the EST and the geometric geoid models were defined and thereafter the polynomial fit was applied. For both EST models a root mean square error of postfitting residuals at GPS-levelling points on the level of $3 \mathrm{~cm}$ was achieved, whereas the range of post-fitted residuals varied from -0.08 to $+0.05 \mathrm{~m}$ (cf. Table 3 ). For the most of Estonia the absolute value of post-fitted residuals is within $2 \mathrm{~cm}$. It could be concluded that the accuracy of least squares modification is at least in the same level as is the accuracy of the used control points. The major changes of the new geoid model occur in the southwestern part of the test area. There are only a few control points available (cf. Fig. 9) and thus have little impact on comparisons with GPS-levelling data.

From the computations the following conclusions can be drawn. No clear improvement of numerical statistics (see post-fitting residuals) is observed in such a small test area, but it could become more evident when producing similar calculations over larger areas. As a matter of fact, a further study by Ellmann (2004) exploits more extended datasets and eventually confirms this presumption. We are thus more confident with the EST-03 geoid, which utilizes GGM01s as the reference model. This is also supported by the comparison of the standard deviation value $(\approx 0.04 \mathrm{~m})$ of pre-fitting residuals $\delta N$ with the RMS of the postfitting residuals $(\approx 0.03 \mathrm{~m})$, which indicates a one-dimensional offset between GPS-levelling points and the EST-03 model. Such parallelism between the practical realization of the national vertical datum and EST-03 geoid model gives an impression of greater reliability, in contrast to the tilted EST-01 model.

\section{CONCLUSIONS}

High-precision tracking data of the orbital perturbations of GRACE twinsatellites provide accurate gravity information with a spatial resolution of $200 \mathrm{~km}$. These data are the basis of the new geopotential model GGM01, released in July 2003. The magnitude of the contribution of different spectral windows of the GGM01s-derived geoid signal was compared with that of the EGM96 model. The discrepancies between long-wavelength contributions of the models reveal most likely the improvements by GRACE, especially in the subpolar latitudes. Thus, even 
in the gravimetrically well studied area like the Baltic Sea region, the new satellite gravity missions may improve the knowledge of the gravity field significantly.

Long-wavelength characteristics of the gravity field are suitable for many studies and different disciplines. For example, the gravity field parameters provide a complementary tool for the study of processes in the Earth's interior. Similar to some earlier geopotential models, a residual geoid of degrees 11 to 35 is depressed in the centre of the study area. This depression is mainly attributed to the postglacial rebound and may also have side-effects from crustal variations.

Further numerical tests involved two sets of high-precision GPS-levelling points in Estonia and Sweden. The results of this study seem to support common expectations that the offset between the national vertical datums can be defined from the comparisons with the geoid models derived from the new satellite data. Thus, the future global geopotential models could lead to unification of different height systems not only within a continent but also overseas. In this respect of particular interest is the first satellite gradiometric mission GOCE to be launched in 2006 by the European Space Agency. This mission will make available unprecedented accuracy for geopotential coefficients in the global scale and up to degree and order 270 (corresponding to the spatial resolution of $65 \mathrm{~km}$ ). The future GRACE models utilizing data from a longer time-span become also very useful.

The new model GGM01s was employed for Estonian geoid modelling by the least squares modification of Stokes' formula. The resulting EST-03 model was validated by fitting this to a set of 26 high-precision GPS-levelling points and verification with an earlier model. Unlike an earlier model, a more realistic onedimensional offset between EST-03 and the practical realization of the national height system was identified. An accuracy of $3 \mathrm{~cm}$ was achieved for post-fitting residuals, which indicates the suitability of the EST-03 geoid model for many practical and scientific applications.

\section{ACKNOWLEDGEMENTS}

The author is grateful to Prof. L. Sjöberg for a constructive review of an earlier version of the manuscript. This research has been supported financially by the Kami Research Foundation. Thanks are also extended to Drs. H. Nahavandchi and J. Plado for their time and effort taken to review this paper.

\section{REFERENCES}

Anderson, A. J. 1984. Geophysical interpretations of features in marine geoid of Fennoscandia. Mar. Geophys. Res., 7, 191-203.

Ardalan, A., Grafarend, E. \& Kakkuri, J. 2002. National height datum, the Gauss-Listing geoid level value $w_{0}$ and its time variation $\hat{w}_{0}$ (Baltic Sea Level Project: epochs 1990.8, 1993.8, 1997.4). J. Geod., 76, 1-28. 
Bouman, J. 2000. Quality Assessment of Satellite-Based Global Gravity Field Models. Netherlands Geodetic Commission, Publications on Geodesy 48, Delft.

Ellmann, A. 2001. Least Squares Modification of Stokes Formula with Application to the Estonian Geoid. Licentiate Thesis in Geodesy, Geodesy Report No. 1056, Royal Institute of Technology (KTH), Stockholm.

Ellmann, A. 2002. An improved gravity anomaly grid and a geoid model for Estonia. Proc. Estonian Acad. Sci. Geol., 51, 199-214.

Ellmann, A. 2004. The Geoid for the Baltic Countries Determined by the Least Squares Modification of Stokes' Formula. Doctoral Dissertation, Geodesy Report No. 1061, Royal Institute of Technology (KTH), Stockholm.

Ellmann, A. \& Sjöberg, L. E. 2002. Combined topographic effect applied to the biased type of the modified Stokes formula. Boll. Geod. Sci. Aff., 61, 207-226.

Ekman, M. \& Mäkinen, J. 1996. Recent postglacial rebound, gravity change and mantle flow in Fennoscandia. Geophys. J. Int., 126, 229-234.

Forsberg, R., Kaminskis, J. \& Solheim, D. 1997. Geoid of the Nordic and Baltic Region from gravimetry and satellite altimetry. In Gravity, Geoid and Marine Geodesy (Segawa, J., Fujimoto, H. \& Okubo, S., eds.), IAG Symp. Series, 117, 540-547.

Heiskanen, W. A. \& Moritz, H. 1967. Physical Geodesy. Freeman \& Co, San Francisco.

Ihde, J., Adam, J., Gurtner, W., Harsson, B. G., Sacher, M., Schlüter, W. \& Wöppelmann, G. 2000. The Height solution of the European Vertical GPS Reference Network (EUVN). In Reports of the EUREF Technical Working Group (Torres, J. A. \& Hornik, H., eds.), Veröff. Bayer. Kom. Int. Erdmess. Bayer. Akad. Wiss.: Astron.-geod. Arb., 2000, 61, 132-145. München.

Kakkuri, J. 1997. Postglacial deformation of the Fennoscandian crust. Geophysica, 31, 99-109.

Kakkuri, J. \& Wang, Z. T. 1998. Structural effects of the crust on the geoid modeled by using deep seismic sounding interpretations. Geophys. J. Int., 135, 495-504.

Lambeck, K. 1988. Geophysical Geodesy. Clarendon Press, Oxford.

Lemoine, F. G., Kenyon, S. C., Factor, J. K., Trimmer, R. G., Pavlis, N. K., Chinn, D. S., Cox, C. M., Klosko, S. M., Luthcke, S. B., Torrence, M. H., Wang, Y. M., Williamson, R. G., Pavlis, E. G., Rapp, R. H. \& Olson, T. R. 1998. The Development of the Joint NASA GSFC and NIMA Geopotential Model EGM96. NASA/TP-1998-206861.

Luosto, U. 1997. Structure of the Earth's crust in Fennoscandia as revealed from refraction and wide-angle reflection studies. Geophysica, 33, 3-16.

Marti, U. Concepts of a regional geoid determination out of mass models. IAG Symp. Series, IUGG 2003 (forthcoming).

Marquart, G. 1989. Isostatic topography and crustal depth corrections for the Fennoscandian geoid. Tectonophysics, 169, 67-77.

Molodensky, M. S., Eremeev, V. F. \& Yurkina, M. I. 1962. Methods for Study of the External Gravitational Field and Figure of the Earth. Israel program for scientific translations, Jerusalem

Pan, M. \& Sjöberg, L. E. 1998. Unification of vertical datums by GPS and gravimetric geoid models with application to Fennoscandia. J. Geod., 72, 64-70.

Sildvee, H. \& Vaher, R. 1995. Geologic structure and seismicity of Estonia. Proc. Estonian Acad. Sci. Geol., 44, 15-25.

Sjöberg, L. E. 1982. Studies on the Land Uplift and Its Implications on the Geoid in Fennoscandia. Department of Geodesy Report 14, University of Uppsala, Uppsala.

Sjöberg, L. E. 1984. Least Squares Modification of Stokes and Vening-Meinesz Formulas by Accounting for Errors of Truncation, Potential Coefficients and Gravity Data. Department of Geodesy Report 27, University of Uppsala, Uppsala.

Sjöberg, L. E. 1996. The terrain effect in geoid computation from satellite derived geopotential models. Boll. Geod. Sci. Aff., 55, 385-392. 
Sjöberg, L. E. 2001. Topographic and atmospheric corrections of gravimetric geoid determination with special emphasis on the effects of harmonics of degrees zero and one. J. Geod., 75, 283-290.

Sjöberg, L. E. \& Hunegnaw, A. 2000. Some modifications of Stokes formula that account for truncation and potential coefficient errors. J. Geod., 74, 232-238.

Sjöberg, L. E., Nord, T. \& Fan, H. 1994a. The Fennoscandian geoid bulge and its correlation with land uplift and Moho depth. In Gravimetry and Space Techniques Applied to Geodynamics and Ocean Dynamics (Schutz, B. E., Anderson, A., Froidevaux, C. \& Parke, M., eds.), pp. 133-142. Geophys. Monogr., 82; IUGG Volume 17.

Sjöberg, L. E., Fan, H. \& Nord, T. 1994b. Further studies on the Fennoscandian gravity field versus the Moho depth and land uplift. Bull. Geod., 69, 32-42.

Tapley, B., Bettadpur, S., Chambers, D., Cheng, M., Choi, K., Gunter, B., Kang, Z., Kim, J., Nagel, P., Ries, J., Rim, H., Roesset, P. \& Roundhill, I. 2003. Gravity field determination from CHAMP using GPS tracking and accelerometer data: initial results. In First CHAMP Mission Results for Gravity, Magnetic and Atmospheric Studies, 1st CHAMP Science Meeting, 21-24 January, 2002, Potsdam, Germany (Reigber, C., Lühr, H. \& Schwintzer, P., eds.). Springer, Berlin.

Vaníček, P. \& Christou, N. T. (eds.). 1994. Geoid and Its Geophysical Interpretations. CRC Press. Boca Raton, Ann Arbor, London.

Vermeer, M. 1994. A Fast Delivery GPS-Gravimetric Geoid for Estonia. Report of the Finnish Geodetic Institute, 94:1, Helsinki.

\section{GRACE-satelliitide mõju raskusjõuvälja uuringutele Fennoskandia ja Balti mere piirkonnas}

\section{Artu Ellmann}

Maa tehiskaaslasi saab kasutada Maa raskusjõuvälja komponentide määramiseks. GRACE-kaksiksatelliitide vaatlusandmed on aluseks geopotentsiaali uuele mudelile GGM01, mis on avaldatud Texase Ülikooli Kosmoseuuringute Keskuse poolt 2003. a juulis. Mudeli GGM01 kvaliteedi hindamisel Balti mere piirkonnas võrreldakse seda varasema mudeliga EGM96. Arvutused põhinevad raskusjõuvälja sfäärilisel harmoonilisel ekspansioonil. Erinevate mudelite võrdlemisel ilmnevad märkimisväärsed lahknevused, mis ulatuvad geoidi kõrgustes mitme detsimeetrini. Järelikult isegi gravimeetriliselt hästi uuritud piirkondades, nagu Balti mere regioon, võimaldavad uued gravimeetrilised satelliidid raskusjõuvälja andmestikku oluliselt täpsustada. Testimisel kõrgtäpsete GPS-nivelleerimise punktidega avalduvad ka erinevused globaalse geoidi ning Balti mere regiooni riikide kõrgussüsteemide vahel. Seejärel on vabaõhu anomaaliate võrku ning geopotentsiaali mudelit GGM01 kasutatud Eesti gravimeetrilise geoidi kuju määramiseks. Geoidi arvutustöödes on rakendatud vähimruutude meetodil modifitseeritud Stokesi valemit. Eesti geoidi uue mudeli EST-03 täpsushinnanguks ning kõrgussüsteemiga ühildamiseks kasutati 26 kõrgtäpset GPS-nivelleerimise punkti. Jääkerinevuste põhjal on arvutatud ühildamise täpsus $3 \mathrm{~cm}$, mis võimaldab EST-03 mudelit rakendada paljude praktiliste ja teaduslike ülesannete lahendamisel. 